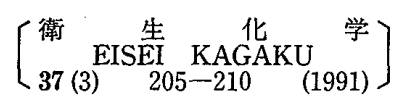

\title{
Hyaluronidase Inhibitor in the Fruit of Citrus reticulata Blanco
}

\author{
Yumie Maeda, ${ }^{a}$ Masatoshi Yamamoto, ${ }^{a}$ Toshio Masui, ${ }^{a}$ Kiyoshi Sugiyama, ${ }^{b}$ \\ Masami Yokota, ${ }^{b}$ Nagahisa Okada, ${ }^{c}$ Kazumi Sugiyama, ${ }^{c}$ \\ Haruki Katayama $^{c}$ and Kazuya Nakagomi ${ }^{d}$
}

Shizuoka Prefectural Institute of Public Health and Environmental Science, ${ }^{a}$ 4-27-2, Kita-ando, Shizuoka 420, Japan, School of Pharmaceutical Science, University of Shizuoka, ${ }^{b}$ 395, Yada, Shizuoka 422, Japan, Shizuoka Prefectural Citrus Experiment Station, ${ }^{c}$ 2-12-10, Komagoe-Nishi, Shimizu 424, Japan and Fermentation Research Institute, ${ }^{d}$ 1-1-3, Higashi, Tsukuba, 305, Japan

(Received December 18, 1990)

Fifty percent of ethanolic extracts from the immature fruits of Citrus reticulata Blanco, C. tamurana hort. ex Tanaka, C. natsudaidai Hayata and C. unshiu Markovich showed a significant inhibitory effect on the activation of inactive hyaluronidase induced by compound $48 / 80$. This effect decreased with the maturation of the fruit in all cases. Among the citrus fruits tested, the extract from the immature $C$. reticulata Blanco showed the strongest inhibitory effect. The data of gel permeation chromatography and gas chromatography-mass spectrometry showed the hyaluronidase inhibitor in the fruit to be a pectin with a molecular weight of $1.1 \times 10^{5}$. The content of D-galacturonic acid in the pectin was determined to be $58 \%$ using the carbazole method. The pectin showed almost the same inhibitory effect $\left(\mathrm{IC}_{50}: 91 \mu \mathrm{g} / \mathrm{ml}\right)$ as a commercial pectin from oranges or a current anti-allergic agent, disodium cromoglycate.

Hyaluronidase has been suggested to be one of the target enzymes controlling the degranulation of mast cells, and the inhibitory effect on the activation of inactive hyaluronidase has been reported by Kakegawa et al. (Chem. Pharm. Bull. 33 [1985]) to be an index of anti-allergic activity. Therefore, it is expected that the pectin in $C$. reticulata Blanco might possess anti-allergic potential.

Keywords - Citrus fruit; Citrus reticulata Blanco; hyaluronidase inhibitor; pectin; polysaccharide; D-galacturonic acid; anti-allergic effect

\section{Introduction}

Citrus fruits have long been used as aromatic stomachics, carminatives, expectorants, antitussives, etc. Recently, the inhibitory effects of these fruits on $48 \mathrm{~h}$ homologous passive cutaneous anaphylaxis and on histamine release from rat peritoneal mast cells have been reported. ${ }^{1)}$ Kubo et $a l .{ }^{1 c)}$ also demonstrated that the immature fruit of Citrus unshiu MARKovicH has strong antiallergic effect against types I, II and IV allergic reactions. From these findings, it has been gradually recognized that citrus fruits might have the potential to inhibit various allergies. To demonstrate this potential more clearly, it is necessary to identify the most effective among the citrus fruits and to isolate the effective component.

Kakegawa et $a l^{2 a)}$ demonstrated that compound 48/80, a non-specific histamine releaser from mast cells, strongly activated hyaluronidase, and, further, that hyaluronidase activated by compound $48 / 80$ was inhibited by anti-allergic agents such as disodium chromoglycate (DSCG) or tranilast. 
We have therefore been attempting the last few years to identify the anti-allergic principles from natural products using a hyaluronidase activation test described by Kakegawa et $a l_{.}{ }^{2 a)}$ We previously reported that tea extracts inhibited the activation of inactive hyaluronidase induced by compound $48 / 80$ $\left(\mathrm{IC}_{50} ; 0.5-1.2 \mathrm{mg} / \mathrm{ml}\right)$, and that phenolic compounds such as tannins in the extracts were responsible for the effect. ${ }^{3)}$ We also isolated two pectins $\left(\mathrm{IC}_{50}: 45 \mu \mathrm{g} / \mathrm{ml}\right)$ as the hyaluronidase inhibitors from Gymnema sylvestre $\mathrm{R} . \mathrm{Br}^{4}{ }^{4}$

In the present study, we investigated the inhibitory effects of the fruits of $C$. reticulata Blanco, $C$. tamurana hort. ex Tanaka, $C$. natsudaidai Hayata, and C. unshiu Markovich on the activation of inactive hyaluronidase induced by compound $48 / 80$. We then tried to isolate the hyaluronidase inhibitors in the immature fruit of $C$. reticulata Blanco, which has shown the strongest inhibitory effect on the activation step in this study.

\section{Experimental}

Materials — Fruits of $C$. reticulata BlANCO, C. tamurana hort. ex TANAKA, C. natsudaidai Hayata and $C$. unshiu MaRKOvich cultivated in Shizuoka Prefectural Citrus Experimental Station were harvested from June to December in 1988-1990. They were cut into round slices, dried and extracted twice with $50 \%$ ethanol. The extract was lyophilized.

Reagents for Measuring Inhibitory Effects of Hyaluronidase _- Hyaluronidase (from bovine testis), hyaluronic acid potassium salt (from rooster comb) and compound 48/80 were purchased from Sigma Chemical Co., Wako Pure Chemical Co. and Sigma Chemical Co., respective1y. DSCG was supplied by Fujisawa Pharmaceutical Co., Ltd.

Other Reagents - Pectin (from oranges, Sigma Chemical Co.) D-galacturonic acid (Wako Pure Chemical Co.), hesperidin (Kanto Chemical Co.), naringin (Bio Chemika Co.), pullulans (Shodex standard P-82, Showa Denko Co.) and a trimethylsilyl ethers kit OT-3 (Shinwa Chemical Industries, Ltd.)) were used.

Assay of Inhibitory Effects of Hyaluronidase — Hyaluronidase activity was determined by the method of Davidson and Aronson ${ }^{5)}$ after incubation of $400 \mathrm{NF}$ unit/ml of hyaluronidase with $0.4 \mathrm{mg} / \mathrm{ml}$ hyaluronic acid potassium salt at $37^{\circ} \mathrm{C}$ for $40 \mathrm{~min}$ in $0.1 \mathrm{M}$ acetate buffer of $\mathrm{pH}$ $4.0{ }^{2 b)}$ Inhibitory effects on the activation of inactive hyaluronidase induced by compound $48 / 80$ $(0.1 \mathrm{mg} / \mathrm{ml})$ were determined using the method described. ${ }^{2 b)}$ Fifty percent inhibitory concentration $\left(\mathrm{IC}_{50}\right)$ was calculated using the mean of 3 observations at each point of 7 concentrations.

Isolation of Hyaluronidase Inhibitor from C. reticulata Blanco - The hyaluronidase inhibitor in the fruit of $C$. reticulata Blanco was purified by the following method. One hundred grams of the dried fruit was extracted with 11 of methanol at $70^{\circ} \mathrm{C}$ for $3 \mathrm{~h}$. After cooling, the mixture was filtered to give a methanol-extract ( $\mathrm{MeOH}$ ext). The residue was further extracted with 11 of water at $90^{\circ} \mathrm{C}$ for $3 \mathrm{~h}$. After cooling, the mixture was filtered to give a water-extract $\left(\mathrm{H}_{2} \mathrm{O}\right.$ ext). Five liters of ethanol was added to the $\mathrm{H}_{2} \mathrm{O}$ ext to form precipitates (EtOH ppt) and the EtOH ppt was collected by filtration. The EtOH ppt was dissolved in water, and separated by gel permeation chromatography (GPC) to give the hyaluronidase inhibitor. GPC was performed on a TSK-GEL G4000 SW column $(21.5 \mathrm{~mm}$ i.d. $\times 300$ $\mathrm{mm})$ (Tosoh) in an oven at $25^{\circ} \mathrm{C}$, with water as a mobile phase and at a flow rate of $3.0 \mathrm{ml} / \mathrm{min}$. The eluted materials were monitored with a differential refractometer (RI-8000, Tosoh).

Determination of Molecular Weight The molecular weight of the hyaluronidase inhibitor in the extract from $C$. reticulata Blanco was determined by GPC using pullulans (Shodex standard P-82) as a standard for calibration curve. GPC was conducted on a TSK-GEL G4000 SW column ( $7.0 \mathrm{~mm}$ i.d. $\times 300 \mathrm{~mm}$ ) (Tosoh) in an oven at $25^{\circ} \mathrm{C}$, with water as a mobile phase at a flow rate of $0.5 \mathrm{ml} / \mathrm{min}$. The eluted materials were monitored with a differential refractometer.

Hydrolysis of the Hyaluronidase Inhibitor 
The purified hyaluronidase inhibitor $(1 \mathrm{mg})$ was dissolved in $10 \% \mathrm{HCl}(5 \mathrm{ml})$, and the solution was heated at $150^{\circ} \mathrm{C}$ in an oil bath for $20 \mathrm{~min}$. The reaction mixture was trimethylsilylated (TMS) by the OT-3 kit, and the derivative was subjected to gas chromatography-mass spectrometry (GCMS). GC-MS was performed under the following conditions. Column, $2 \%$ OV-17 on Uniport HP $(80 / 100$ mesh) $3 \mathrm{~mm}$ i.d. $\times 2 \mathrm{~m}$ glass column; carrier gas, $\mathrm{He} 40 \mathrm{ml} / \mathrm{min}$; temp., col. $160^{\circ} \mathrm{C}$, inj. $200^{\circ} \mathrm{C}$, ion source $190^{\circ} \mathrm{C}$; ionization voltage, 70 $\mathrm{eV}$; instrument, M-80A (Hitachi).

\section{Results and Discussion}

1. Inhibitory Effects of Citrus Fruits on the Activation of Inactive Hyaluronidase

The inhibitory effects of $50 \%$ ethanolic extracts from immature and mature citrus fruits on the activation of inactive hyaluronidase are shown in Table I. All of the fruits inhibited the activation step, with the effects of the immature fruits being stronger than those of the mature fruits. Especially, in $C$. reticulata BLANCO, $\mathrm{IC}_{50}$ of the immature fruit decreased to about one thirty-third that of the mature fruit, and was the lowest of the values among the fruits tested.

Immature fruit of $C$. unshiu MARKovicH has been reported to exhibit a strong antiallergic effect against types I, II and IV allergic reactions. ${ }^{10)}$ In the present study, it was found that the inhibitory effect of immature fruit of $C$. reticulata Blanco was about six times stronger than that of immature fruit of C. unshiu MaRKovich, suggesting that the former fruit may have a strong anti-allergic effect.

Table II shows the changes in inhibitory effects of $50 \%$ ethanolic extracts from the fruit of $C$. reticulata Blanco during maturation. These effects weakened with maturation of the fruit, and the immature fruit, harvested in July, showed the strongest inhibitory effect

TABLE I. Inhibitory Effects of 50\% Ethanolic Extract from Citrus Fruits on Activation of Inactive Hyaluronidase by Compound $48 / 80$

\begin{tabular}{lcc}
\hline \multirow{2}{*}{ Material } & \multicolumn{2}{c}{$\mathrm{IC}_{50}(\mathrm{mg} / \mathrm{ml})^{a)}$} \\
\cline { 2 - 3 } & Immature $^{b)}$ & Mature $^{c)}$ \\
\hline Citrus reticulata BLANCO & 0.5 & 17.4 \\
Citrus tamurana hort.ex TANAKA & 3.0 & 64.0 \\
Citrus natsudaidai HAYATA & 6.2 & 40.0 \\
Citrus unshiu MARKOVICH & 3.0 & N.T. ${ }^{d)}$ \\
\hline
\end{tabular}

a) Fifty \% inhibitory concentration.

b) Harvested in July.

c) Harvested in December.

d) Not tested.

TABLE II. Changes in Inhibitory Effect of 50\% Ethanolic Extract from Citrus reticulata Blanco on Activation of Inactive Hyaluronidase during Maturation

\begin{tabular}{cccccccc}
\hline Material & & Date of harvest & $\begin{array}{c}\text { Weight } \\
(\mathrm{g})\end{array}$ & $\begin{array}{c}\text { Diameter } \\
(\mathrm{cm})\end{array}$ & $\begin{array}{c}\text { Yield }^{a)} \\
(\%)\end{array}$ & $\begin{array}{c}\mathrm{IC}_{50}{ }^{b)} \\
(\mathrm{mg} / \mathrm{ml})\end{array}$ \\
\hline Citrus reticulata & 1 & 1989. & 7.24 & $7.2-9.2$ & $2.4-2.5$ & $7.2 \pm 0.1$ & 0.5 \\
BLANCO & 2 & 9.21 & $41.4-53.8$ & $4.4-4.7$ & $5.5 \pm 0.2$ & 2.8 \\
& 3 & 10.26 & $80.0-96.7$ & $5.7-6.0$ & $6.1 \pm 0.2$ & 8.0 \\
& 4 & 12.8 & $115.2-144.4$ & $6.2-7.0$ & $8.0 \pm 0.2$ & 17.4 \\
\hline
\end{tabular}

a) Yield of $50 \%$ ethanolic extract from citrus fruits. Mean \pm S.D.

b) Fifty \% inhibitory concentration. 
$\left(\mathrm{IC}_{50}=0.5 \mathrm{mg} / \mathrm{ml}\right)$.

2. Isolation of Hyaluronidase Inhibitor from $C$. reticulata Blanco

In our preliminary experiment, the wellknown constituents in citrus fruits, such as hesperidin, naringin and synephrine, little inhibited the activation of inactive hyaluronidase at a concentration of $2.0 \mathrm{mg} / \mathrm{ml}$. Hyaluronidase inhibitor was therefore isolated from the immature fruit of $C$. reticulata Blanco harvested in July (Chart 1). Since the $\mathrm{H}_{2} \mathrm{O}$ ext showed stronger effect than the $\mathrm{MeOH}$ ext, the $\mathrm{H}_{2} \mathrm{O}$ ext was further fractionated by the addition of ethanol. The inhibitory effect of the $\mathrm{H}_{2} \mathrm{O}$ ext was recovered mainly in the EtOH ppt. The active constituent purified from the EtOH ppt by GPC, which was detected as a single peak on the chromatogram (Fig. 1), showed strong inhibitory effect at $91 \mu \mathrm{g} / \mathrm{ml}$ of $\mathrm{IC}_{50}$. On the basis of the yield and $\mathrm{IC}_{50}$ value, it appears that the active constituent makes a large contribution

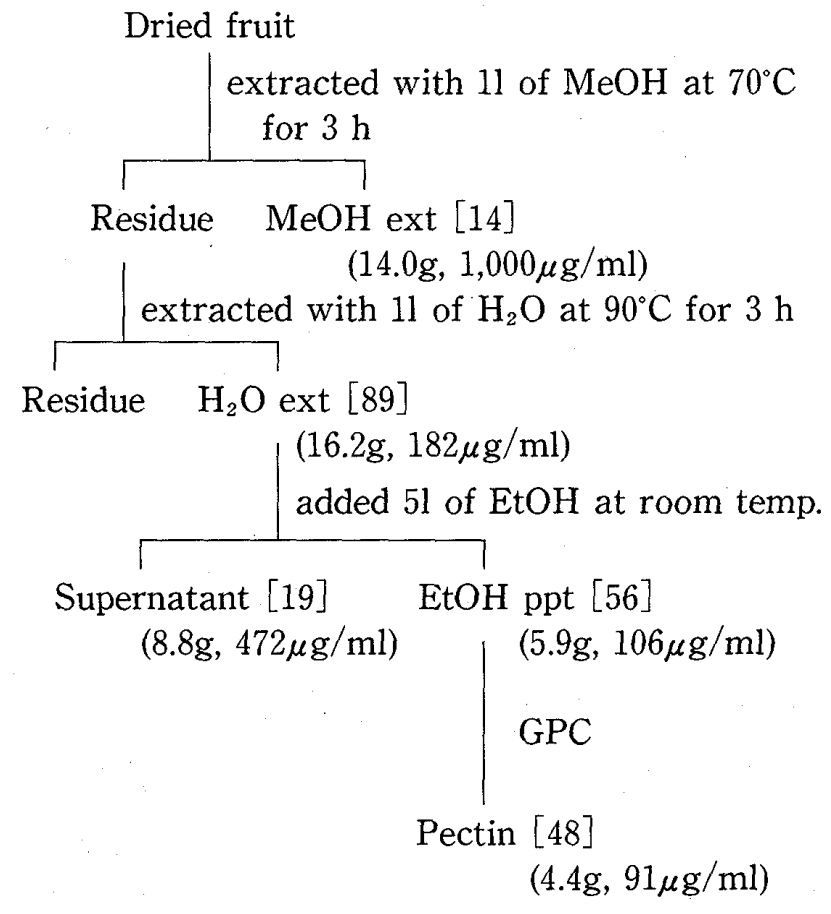

Chart 1 Isolation Procedure of Hyaluronidase Inhibitor from Citrus reticulata BLANCO

Each yield $(\mathrm{g})$ and each $50 \%$ inhibitory concentration $\left(\mathrm{IC}_{50}\right.$ : $\mu \mathrm{g} / \mathrm{ml}$ ) of fractions from $100 \mathrm{~g}$ of dried Citrus reticulata BLANCo is indicated in parenthesis.

Each total activity (yield $/ \mathrm{IC}_{50} \times 10^{3}$ ) is indicated in brackets. to the production of the inhibitory effect of the fruit.

3. Properties of the Hyaluronidase Inhibitor of $C$. reticulata Blanco

The molecular weight of the active constituent was estimated to be $1.1 \times 10^{5}$ using GPC (Fig. 2). The constituent showed a pur-

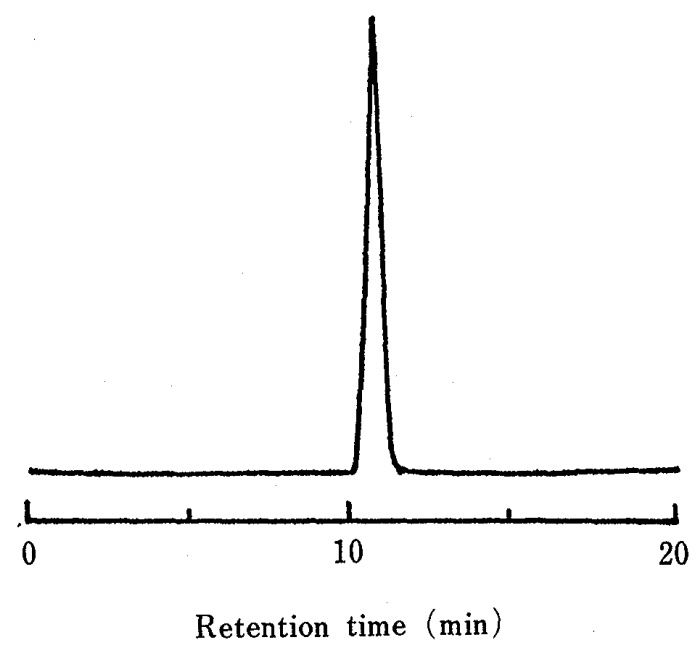

Fig. 1. Gel Permeation Chromatogram of the Hyaluronidase Inhibitor in the Extract from Citrus reticulata Blanco

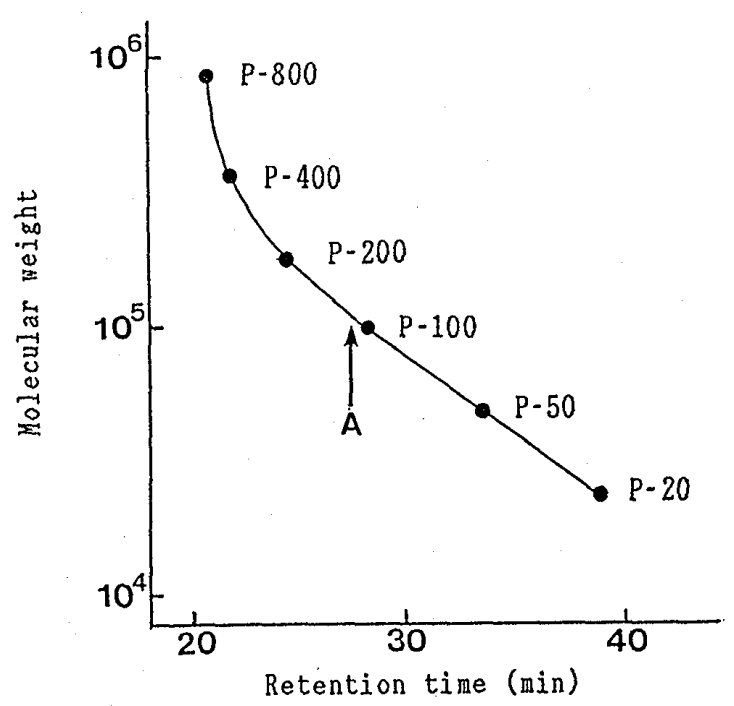

Fig. 2. Molecular Weight Determination of the Hyaluronidase Inhibitor in the Extract from Citrus reticulata Blanco by Gel Permeation Chromatography on a TSKGel G4000 SW

Sample-A: hyaluronidase inhibitor in the extract from Citrus reticulata B BANCo; P-800 (MW : $8.53 \times 10^{5}$ ), P-400 (MW: $3.8 \times 10^{5}$ ), P-200 (MW: $\left.1.86 \times 10^{5}\right)$, P-100 (MW: $1.0 \times 10^{5}$ ), P-50 (MW : $4.8 \times 10^{4}$ ) and P-20 (MW: $2.37 \times 10^{4}$ ) : pullulans (Shodex Standard P-82). 
ple color by Molisch reaction ${ }^{6}$ known as a qualitative reaction of the saccharide, and an absorption maximum near $480 \mathrm{~nm}$ by the phenol $-\mathrm{H}_{2} \mathrm{SO}_{4}$ method. ${ }^{7)}$ The acid hydrolysis product of the constituent reduced the Fehling solution, although the constituent by itself did not.

From the above results, the hyaluronidase inhibitor was suggested to be a substance containing saccharides with a molecular weight of $1.1 \times 10^{5}$.

The acid hydrolyzed product of the active constituent was trimethylsilylated, and the TMS derivative was analyzed by GC-MS to identify constituting monosaccharides. Though several peaks were detected on GCMS chromatograms, which were suggested to be TMS-saccharides by their mass spectra, only the retention time $(9.7 \mathrm{~min})$ of a peak agreed with that of a TMS derivative of D-galacturonic acid as a standard; the mass spectrum of the peak also agreed with that of the standard. Furthermore, the content of D-galacturonic acid in the active constituent was determined as $58 \%$ by the carbazole method. ${ }^{8)}$

Pectin is well-known to be a polysaccharide in cell walls of all plant tissues, and occurs naturally as the partial methyl ester of $\alpha$ - (1 $\rightarrow 4$ ) linked D-galacturonate sequences. Its molecular weight has been reported to be from $1.0 \times 10^{5}$ to $\left.1.5 \times 10^{6} .^{9}\right)$ The TMS derivatives of the acid hydrolyzed active constituent showed the same retention time and mass spectra as those of the TMS derivatives of the acid hydrolyzed commercial orange pectin.

Based on the above results, the hyaluronidase inhibitor of the fruit of $C$. reticulata BLANCO was suggested to be a pectin containing $58 \%$ D-galacturonic acid with molecular weight of $1.1 \times 10^{5}$. The hyaluronidase inhibitor from $C$. reticulata Blanco showed almost the same inhibitory effect as that of the commercial orange pectin $\left(\mathrm{IC}_{50}: 47 \mu \mathrm{g}\right.$ / $\mathrm{ml})$ and a current anti-allergic drug, DSCG $\left(\mathrm{IC}_{50}: 110 \mu \mathrm{g} / \mathrm{ml}\right)$ on the activation of inactive hyaluronidase.

We recently isolated two pectins with molecular weights of $4.0 \times 10^{4}$ and $2.0 \times 10^{4}$, as the hyaluronidase inhibitor $\left(\mathrm{IC}_{50}: 45 \mu \mathrm{g} / \mathrm{ml}\right.$ ) from Gymnema sylvestre $\mathrm{R}$. $\mathrm{Br}^{4}{ }^{4}$ The pectin with a molecular weight of $1.1 \times 10^{5}$ from $C$. reticulata BLANCO showed about half the inhibitory effect as that of the pectin from Gymnema sylvestre $\mathrm{R}$. Br. We further found that the effect of $C$. reticulata Blanco decreased with the maturation of the fruit. Thus, the inhibitory effect of pectins might be related to their structure. It is interesting to examine this effect of various kinds of pectins on the activation of inactive hyaluronidase and to learn the relation of the structures to the effect. Isolation of pectins from natural products is now in progress in our laboratory.

Acknowledgement We are grateful to Mr. Yoshiyuki Sawabe, Osaka Prefectural Institute of Public Health, for his helpful advice and timely guidance throughout this study.

\section{References}

1) a) A. Koda, T. Nishiyori, H. Nagai, N. Matsuura and H. Tsuchiya, Folia Pharmacol. Japan. 80, $31(1982)$; b) U. Sankawa, J. Traditional Sino-Japanese Medicine, 5, 52 (1984) ; c) M. Kubo, M. Yano and H. Matsuda, Yakugaku Zasshi, 109, 835 (1989).

2) a) H. Kakegawa, N. Mituo, H. Matsumoto, T. Satoh, M. Akagi and K. Tasaka, Chem. Pharm. Bull., 33, 642 (1985) ; b) Y. Maeda, M. Yamamoto, T. Masui and K. Nakagomi, Bull. Shizuoka Pref. Inst. Publ. Hlth. and Environ., 30, 41 (1987).

3) Y. Maeda, M. Yamamoto, T. Masui, K. Sugiyama, M. Yokota, K. Nakagomi, H. Tanaka, I. Takahashi, T. Kobayashi and E. Kobayashi, J. Food. Hyg. Soc. Jpn, 31, 233 (1990). 
4) Y. Sawabe, S. Iwagami, Y. Maeda, K. Nakagomi, S. Suzuki and H. Nakazawa, Eisei Kagaku, 36, 314 (1990).

5) E.A. Davidson and N.N. Aronson, J. Biol. Chem., 242,437 (1967).

6) Molisch, Monatsh., 7, 2856 (1886).

7) M. Dudois, K. Gilles, J.K. Hamilton, P.A. Rebers and F. Smith, Anal. Chem., 28, 350 (1956).

8) T. Bitter and H.M. Muir, Anal. Biochem., 4, 330 (1962).

9) S. Yoshizumi, H. Ito and T. Kokubu, "Genealogy of Sweetness and its Science," 332, Kohrin, Tokyo, (1986). 